\title{
Relación entre los ácidos biliares y la microbiota intestinal ¿es posible considerarlo como un factor etiológico en diversas colangiopatías? Una revisión narrativa
}

\author{
Relationship between bile acids and intestinal microbiota, can it be considered \\ an etiological factor in various cholangiopathies? A narrative review \\ Relação entre os ácidos biliares e a microbiota intestinal, é possivel considerá-la como \\ fator etiológico em várias colangiopatias? Revisão de tem
}

Ana M. Jaillier-Ramírez', Dan Waitzberg'ㄹ, Andrés Becerra Romero ${ }^{3}$

Recibido: 1 de marzo de 2021. Aceptado para publicación: 21 de abril de 2021.

Publicado en línea: 17 de junio de 2021

https://doi.org/10.35454/rncm.v4n4.287

\section{Resumen}

Los ácidos biliares, cuyo precursor es el colesterol de la dieta, tienen una importancia fundamental en el metabolismo de los lípidos ingeridos, siendo tal vez su función más divulgada. Sin embargo, estos interactúan de manera recíproca con el metabolismo bacteriano intestinal, mediante las señales moleculares, que permiten una modificación tanto en la abundancia como en la diversidad de la microbiota intestinal. Esta última se ha considerado como el nuevo órgano, y ha tenido un estudio a profundidad en los últimos años gracias a los avances y la optimización en los métodos diagnósticos, lo que permite determinar su implicación en enfermedades no solo del tracto gastrointestinal, sino a nivel sistémico. El objetivo de la presente revisión es identificar las diferentes alteraciones en la transformación de los ácidos biliares primarios a secundarios, y cómo estos cambios generan una modificación en la composición de la microbiota intestinal, lo que genera procesos de inflamación crónica, mediado por diferentes vías de señalización, siendo factores etiológicos para un sin número de patologías que comprometen los colangiocitos.

Palabras clave: microbiota, ácidos biliares, colangiopatías.

\section{Summary}

Bile acids, whose precursor is dietary cholesterol, are essential for the metabolism of ingested lipids. This is perhaps the role they are best known for. However, they are also involved in a reciprocal interaction with intestinal bacterial metabolism through molecular signals that allow a change in both the abundance and diversity of the gut microbiota. In recent years, the latter has been considered as the "new organ" and earned an in-depth study facilitated by advances and optimization in diagnostic methods, allowing to determine its role in diseases, not only of the gastrointestinal tract, but also at the systemic level. The objective of this study is to identify the different changes occurring as bile acides transform from primary to secondary, and to determine how these changes modify the composition of the gut microbiota, giving ruse to a chronic inflammation process mediated by different signaling pathways, and how they become significant factors for a number of pathologies that compromise choanocytes.

Keywords: Microbiota; Bile Acid; Cholangiopathy.

\section{Resumo}

Os ácidos biliares, cujo precursor é o colesterol da dieta, são de fundamental importância no metabolismo dos lipídios ingeridos, sendo talvez sua função mais divulgada. No entanto, eles interagem reciprocamente com o metabolismo bacteriano intestinal por meio de sinais moleculares que permitem uma modificação tanto na abundância quanto na diversidade da microbiota intestinal. Esta última foi considerada como o novo órgão e tem merecido um estudo aprofundado nos últimos anos graças aos avanços e a otimização dos métodos diagnósticos, permitindo determinar o seu envolvimento em doenças não só do trato gastrointestinal, mas também a nível sistêmico. O objetivo desta revisão é identificar as diferentes alterações na transformação dos ácidos biliares primários em secundários e como essas alterações geram uma modificação na composição da microbiota intestinal, gerando processos de inflamação crônica mediados por diferentes vias de sinalização, sendo, portanto, fatores etiológicos para uma série de patologias que comprometem o colangiócito.

Palavras-chave: microbiota, ácidos biliares, colangiopatias. 
Departamento de Nutrición, Hospital San Vicente Fundación, Rionegro, Colombia.

2 Facultad de Medicina, Universidad de Sao Paulo, Brasil.

3 Departamento de Cirugía de Trasplantes de Órganos Abdominales, Hospital San Vicente Fundación. Rionegro, Colombia.

\section{INTRODUCCIÓN}

Teniendo en cuenta el gran interés que ha despertado la microbiota y la disbiosis, como factor etiológico en diferentes patologías, tanto inflamatorias como tumorales, principalmente en el tracto gastrointestinal, y considerando el aumento significativo en las lesiones neoplásicas e inflamatorias del tracto biliar, las cuales presentan una alta morbimortalidad, a pesar de la optimización del proceso diagnóstico y eficacia en el proceso terapéutico, se realizó una revisión bibliográfica para evaluar la posible relación entre la microbiota y las diferentes colangiopatías, desde su origen en los ácidos biliares. El objetivo de este trabajo es demostrar la disbiosis como un factor etiológico, lo que permitirá guiar posibles manejos terapéuticos en un futuro cercano. Para tal fin se consultaron las bases de datos de PubMed y Cochrane, con las palabras clave microbiota, ácidos biliares y colangiopatías. Luego se seleccionaron los artículos más relevantes de los últimos años, y se llevó a cabo un análisis crítico de estos.

\section{METABOLISMO DE LOS ÁCIDOS BILIARES}

El colesterol se considera como un verdadero modulador de las señales celulares y de la conducción neuronal $^{(1)}$, además de ser un precursor de las biomoléculas, entre las que se incluyen las hormonas esteroideas, la vitamina D y los ácidos biliares. Del colesterol corporal solo un tercio es de origen dietario o exógeno, principalmente proveniente de alimentos de origen animal, especialmente el huevo y las carnes rojas, los dos tercios restantes se sintetizan por células nucleadas, reconocido como colesterol endógeno ${ }^{(1)}$.

Los ácidos biliares primarios, como el ácido quenodeoxicólico, con dos grupos $\alpha$-hidroxi en las posiciones C-3 y C-7, y el ácido cólico, con un grupo $\alpha$-hidroxi adicional en la posición C-12, se sintetizan a partir del colesterol en el hígado ${ }^{(2)}$. Estos poseen una característica especial de detergentes biológicos anfipáticos, que actúan sobre el metabolismo de los lípidos, entre otros procesos regulatorios (Figura 1$)^{(3)}$.
Correspondencia: Jorge Andrés Becerra Romero. andres.becerra@sanvicentefundacion.com
La síntesis de los ácidos biliares ocurre en el hepatocito mediante la vía clásica y la vía alterna. En la primera, el colesterol se convierte a $7 \alpha$-hidroxicolesterol, como precursor común tanto para el ácido quenodeoxicólico como para el ácido cólico. La vía alterna, la cual ocurre en diferentes tejidos del cuerpo, permite que el colesterol se pueda oxidar a 27-hidroxicolesterol, para luego ser modificado por el oxisterol hidroxilasa CYP7B1 y convertido en los ácidos biliares primarios (Figura 1) $)^{(4)}$.

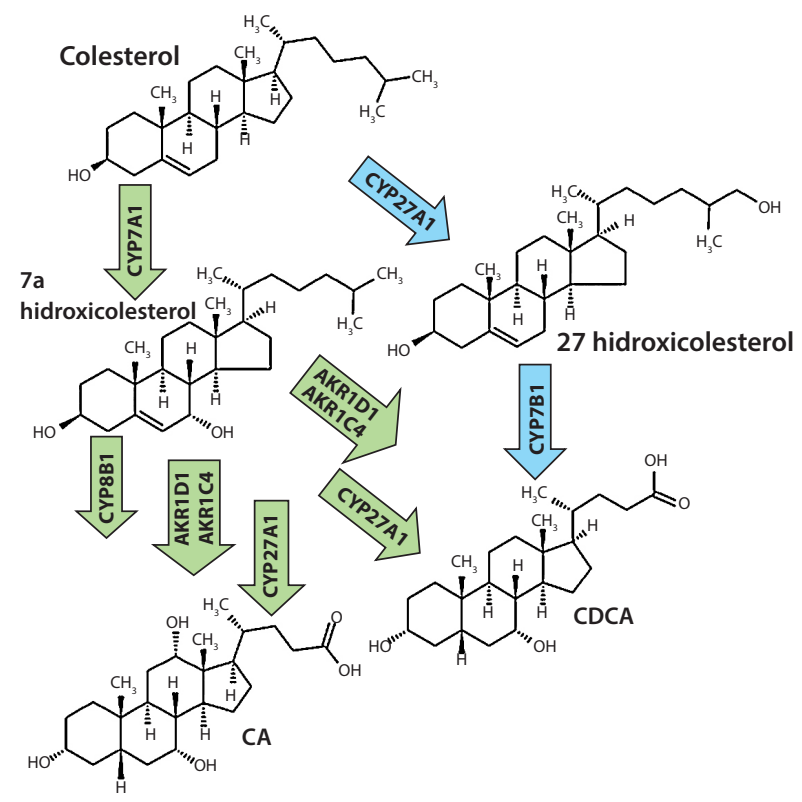

Figura 1. Síntesis de los ácidos biliares en humanos. Las flechas verdes indican el proceso primario de síntesis, mientras las flechas azules representan una vía alternativa. Tomada y modificada de $^{(3)}$.

En el hígado, los ácidos biliares primarios se conjugan con la glicina o la taurina mediante la enzima biliar ácido CoA sintetasa (BACS) y la aminoácido biliar transferasa (BAT), y se almacenan en la en la vesícula biliar ${ }^{(2)}$. Esta conjugación se hace con una tasa de 3:1 de glicina $y$ taurina, respectivamente ${ }^{(1)}$, lo que permite aumentar 
la solubilidad de estos ácidos biliares hidrofóbicos (no polares) y la posibilidad de daño de la membrana.

Luego de la ingesta de alimentos, la vesícula biliar libera los ácidos biliares a la segunda porción del duodeno, donde permite la solubilización de los lípidos ingeridos, los cuales se reabsorben en el íleon distal a través de un transporte activo, con una recuperación del $50 \%-90 \%$ de los ácidos biliares, conjugados mediante la circulación entero hepática ${ }^{(2)}$. Aquellos que no se reabsorben pueden servir de sustrato para el metabolismo microbiano, lo que permite una biotransformación a ácidos biliares secundarios, formados mediante la vía $7 \alpha$-hidroxicolesterol, con la intervención de las bacterias del tracto gastrointestinal ${ }^{(5)}$. El ácido deoxicólico se forma con el ácido cólico y el ácido litocólico, a partir del ácido quenodeoxicólico (Figura 2) ${ }^{(6)}$.
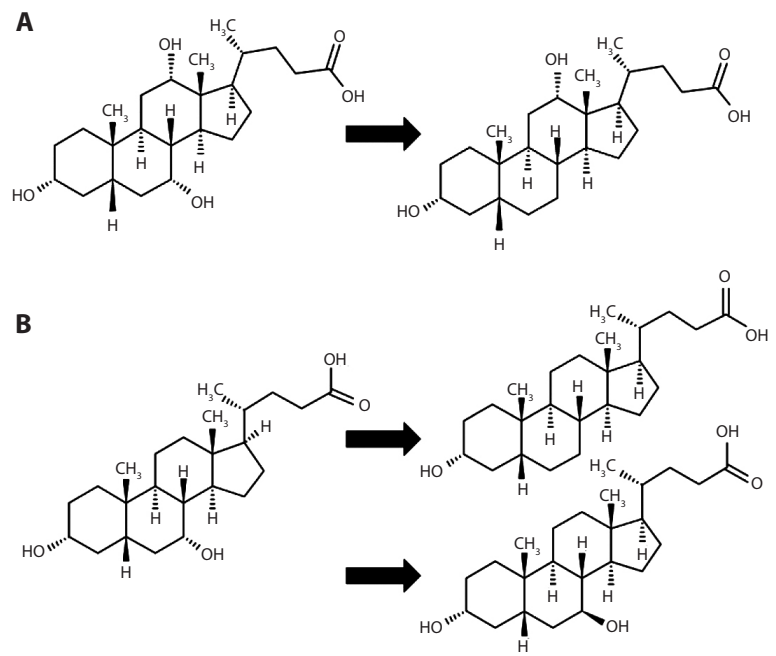

Figura 2. Estructura química de los ácidos biliares secundarios derivados del ácido cólico $(\mathbf{A})$ y del ácido quenodesoxicólico $(\mathbf{B})^{(3)}$.

Una vez los ácidos biliares son llevados al hígado nuevamente, mediante la circulación enterohepática, los ácidos biliares secundarios son conjugados de nuevo; de esta manera, el ácido deoxicólico contribuye al $20 \%$ del grupo de ácidos biliares intrahepáticos, mientras que el ácido litocólico, el cual es altamente tóxico, es sulfatado en la posición C-3, lo que permite una pobre reabsorción y una excreción por las heces ${ }^{(6)}$.

\section{VÍAS REGULADORAS DE LA PRODUCCIÓN DE LOS ÁCIDOS BILIARES}

La composición de los ácidos biliares se regula por el metabolismo bacteriano intestinal, mediante la interacción de señales moleculares en el hospedero, con receptores de ácidos biliares, entre los que se incluyen el receptor X fernesoide (FXR $\alpha$ ), los receptores de la vitamina $\mathrm{D}$ (VDR) y los receptores de los ácidos biliares unidos a la proteína G (TGR5), localizados en la superficie celular ${ }^{(7)}$.

El FXRa es el regulador primario de la síntesis de los ácidos biliares en el hígado, el cual inhibe las enzimas que permiten la síntesis a partir del colesterol. El FXR $\alpha$ se activa por los ácidos biliares, tanto primarios como secundarios, y se une a regiones reguladoras del ADN como un heterodímero con los receptores retinoides $\mathrm{X}^{(8)}$. Estos mecanismos de inhibición varían dependiendo de donde se active el FXR $a$, ya sea en el intestino o en el hígado. Este actúa en este último de manera predominante sobre la vía del CYP7A1, mientras que en el intestino opera mayormente sobre la vía CYP8B1 ${ }^{(9)}$. Su inhibición se asocia con las vías de señalización del receptor del factor de crecimiento epidérmico ${ }^{(10)}$.

De manera llamativa se ha demostrado que la cantidad de los ácidos biliares se asocia con la microbiota presente en el intestino ${ }^{(11)}$. De tal manera, que una alteración en la composición de la microbiota intestinal (MI) ha demostrado un incremento en la reabsorción de los ácidos biliares ${ }^{(12)}$. A su vez, los ácidos biliares se han asociado con un sin número de vías metabólicas e inmunológicas, como se muestra en la Tabla $1^{(13)}$.

\section{MICROBIOTA INTESTINAL}

La MI es un ecosistema diverso y dinámico de microorganismos vivos, que habita en el intestino, principalmente en el colon, donde la densidad de estos es la mayor en nuestro organismo. Se caracteriza tanto por la riqueza de los microorganismos que la componen como por su abundancia. Se estima que la mayoría de los microorganismos presentes son bacterias con más de 500-1000 especies diferentes, según su clasificación taxonómica, la cual muestra agrupaciones por similitudes genéticas o fenotípicas, siendo los filos y géneros, los niveles frecuentemente reportados por la literatura. Dentro de los principales filos bacterianos se destacan los Firmicutes (50 \%) y Bacteroidetes (25\%), y en menor proporción la Actinobacteria, Proteobacteria, Fusobacteria y Verrucomicrobia ${ }^{(14,15)}$. Entre los géneros identificados se encuentra la Bacteroides, Eubacterium, Bifidobacterium, Ruminococcus, Peptostreptococcus, Propionibacterium, Clostridium, Lactobacillus, Escherichia, Streptococcus y Methanobrevibacter ${ }^{(16)}$.

En condiciones ideales, la MI puede presentar una relación simbiótica, la cual puede ser de tres tipos: 
Tabla 1. Efectos regulatorios de los ácidos biliares

\begin{tabular}{|l|c|l|}
\hline \multicolumn{1}{|c|}{ Efecto } & Ácido biliar & Receptor comprometido/mecanismo de acción \\
\hline $\begin{array}{l}\text { Detoxificación/excreción de los componentes } \\
\text { xenobióticos }\end{array}$ & LCA & $\begin{array}{l}\text { Receptor xenobiótico y esteroideo (SXR), receptor X } \\
\text { de pregnano (PXR) }\end{array}$ \\
\hline Detoxificación LCA & LCA y derivados & Receptor de la vitamina D (VDR) \\
\hline Movilización del calcio intracelular & CDCA & $\begin{array}{l}\text { Fosfatidil-inositol-2-cinasa (PI3K) } \\
\text { Inositol trifosfato (IP3) }\end{array}$ \\
& TCA & \\
\hline Activación o inhibición del AMPc & DCA & \\
& TLCA & Tlucagón \\
& CDCA & Proteína cinasa C (PKC) \\
& TCA & \\
& DCA & \\
& TLCA & \\
\hline Activación de la proteína cinasa C & UCA & \\
& CDCA & \\
\hline Inducción de la expresión de interleucina 1 y & TCA & Desconocido \\
factor de necrosis tumoral alfa & TLCA & \\
\hline
\end{tabular}

DCA: ácido desoxicólico; LCA: ácido litocólico; CDCA: ácido quenodeoxicólico; TCA: ácido taurocólico; TUDCA: ácido tauroquenodesoxicólico; TLCA: ácido taurolitocólico.

comensal con el hospedero, donde los microorganismos utilizan el medio ambiente del ser humano para obtener nutrientes, relación que en condiciones normales es inofensiva, pero pueden convertirse en perjudicial si las condiciones medioambientales cambian; de tipo mutualista, en la cual tanto los microorganismo como el huésped se benefician de esta relación, siendo además imprescindibles para el correcto funcionamiento de nuestro cuerpo; y de tipo parasitismo, en la que solo se beneficia el parásito, siendo perjudicial para el huésped ${ }^{(14,17)}$. Así, la MI produce un gran impacto en la fisiología del cuerpo humano en la salud, entre otras, por sus función metabólica y de protección, y también en la enfermedad, por lo que se ha denominado como "el nuevo órgano vital metabólico"(18, 19).

Muchos de los géneros bacterianos, especialmente el Clostridium, se han identificado en la transformación de los ácidos biliares primarios a secundarios ${ }^{(5)}$. Además, las moléculas producidas por todo el microbioma pueden no solo tener un efecto local, sino también sistémico, luego de su paso por el hígado mediante la circulación enterohepática ${ }^{(20)}$, donde, en general, se pueden modificar para eliminar el componente tóxico en la mayoría de los casos. De esta manera, se han asociado con diferentes patologías a nivel sistémico, tal como se muestra en la Figura $3^{(21)}$.

La alteración de la composición de la MI, o disbiosis intestinal, se caracteriza por una disminución en la riqueza y la diversidad microbiana producida por factores intrínsecos o extrínsecos, que pueden dar lugar a enfermedades no solo en el tracto gastrointestinal, sino también a nivel sistémico. Dicha disbiosis puede presentarse mediante tres mecanismos: inmunobioma, endobioma y xenobioma. El primero se define como una interacción representativa entre el sistema inmune del huésped y la MI, con énfasis en una comunicación vía conservativa (por ejemplo, receptores Toll-like [TLR] o vía variable (por ejemplo, receptores de linfocitos $\mathrm{T}$ [TCR] (Figura 4) ${ }^{(21)}$. Por su parte, la endobioma son las vías bioquímicas en la MI, que contribuyen a la fisiología de la enfermedad mediante la síntesis de componentes o moléculas cometabolizadoras, producidas por el hospedero (Figura 5) ${ }^{(21)}$; y finalmente el xenobioma, mecanismo conocido como vías metabólicas en la MI 


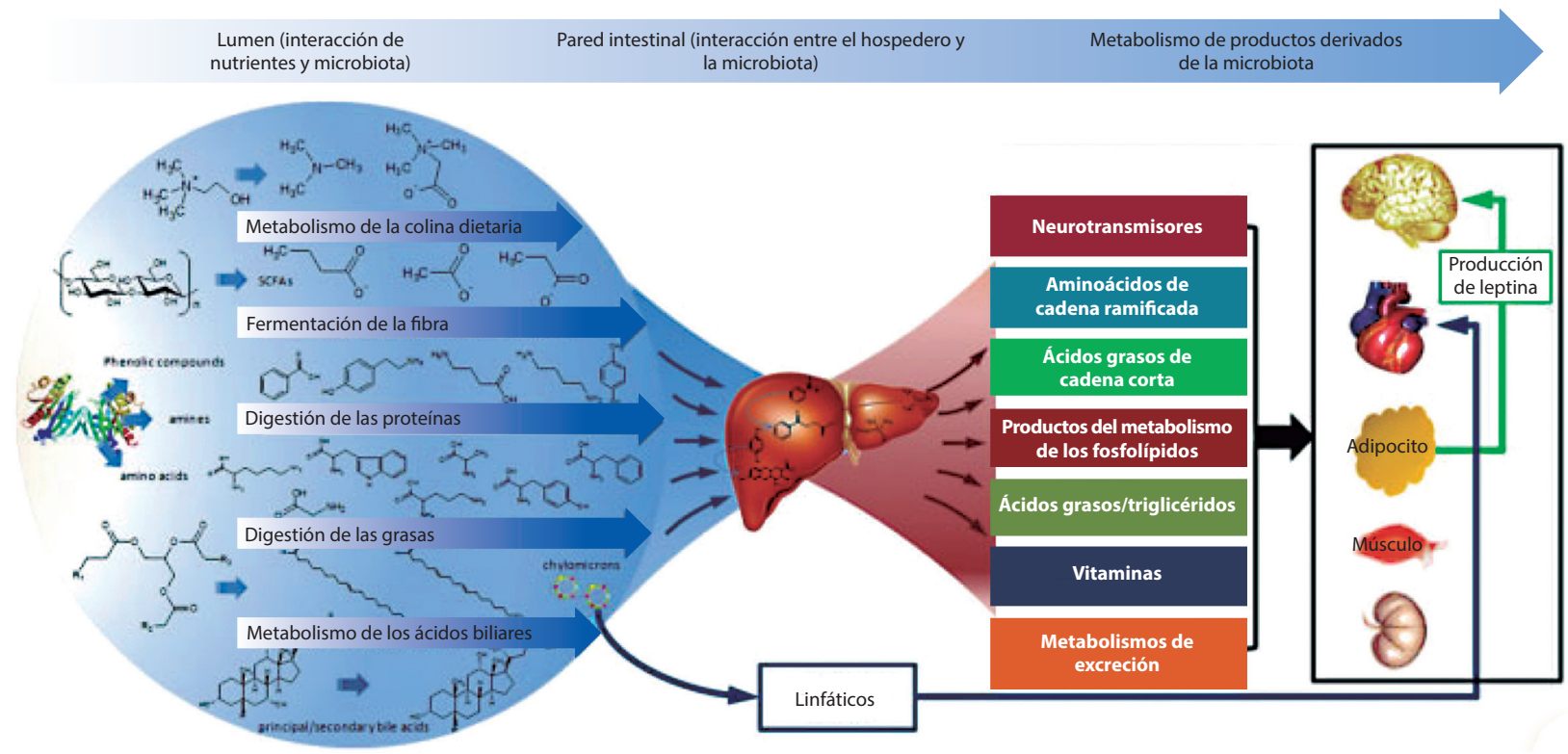

Figura 3. Metabolismo del microbioma y de los efectos en el huésped. Tomada y modificada de ${ }^{(21)}$.

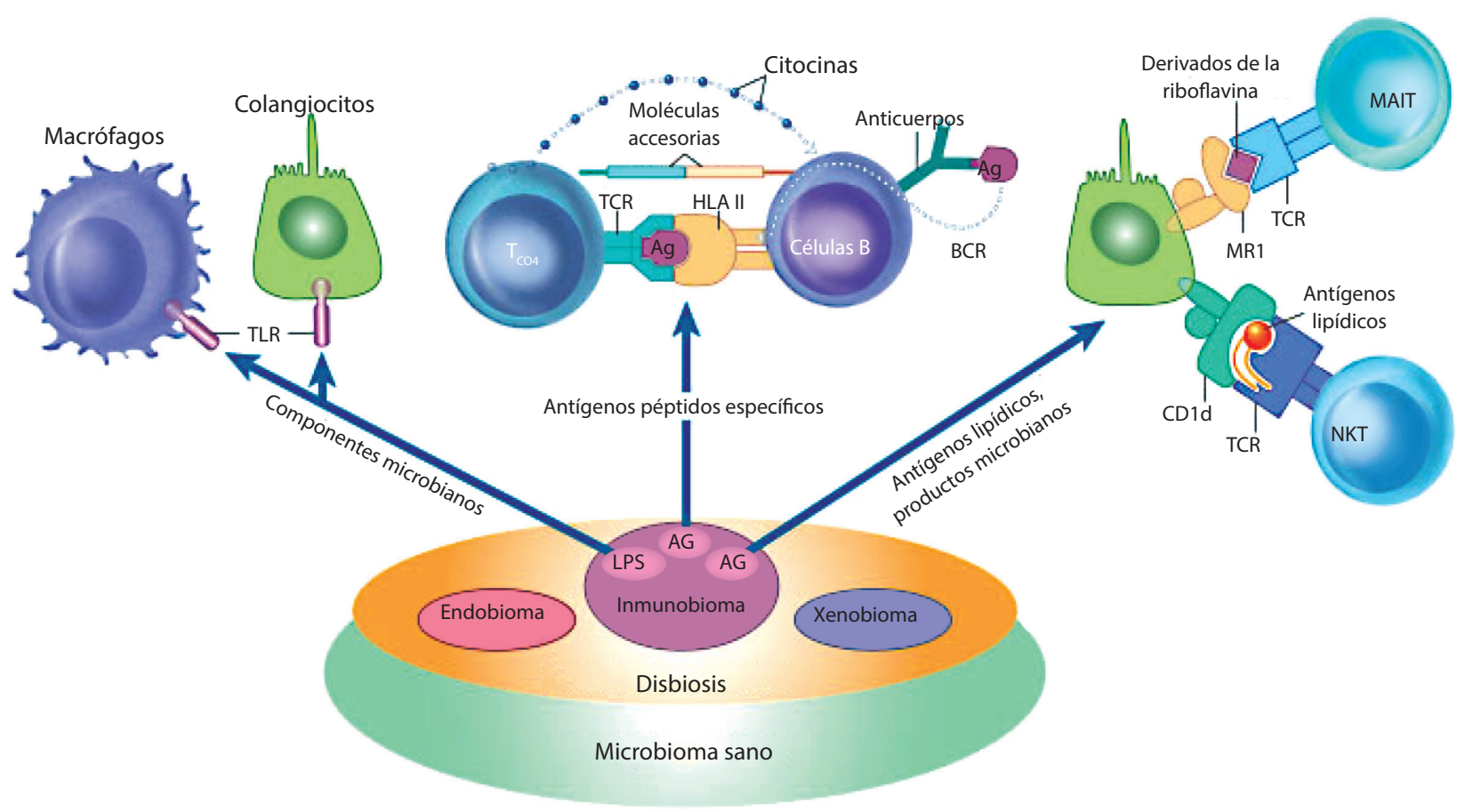

Figura 4. Concepto de la inmunobioma. Tomada y modificada de ${ }^{(21)}$.

envueltas en la transformación de componentes exógenos, incluidos nutrientes, medicamentos y segmentos de productos ambientales (Figura 6) ${ }^{(21)}$.

\section{Métodos de estudio de la microbiota}

Las técnicas moleculares de secuenciación masiva, especialmente las de segunda generación, han permitido 

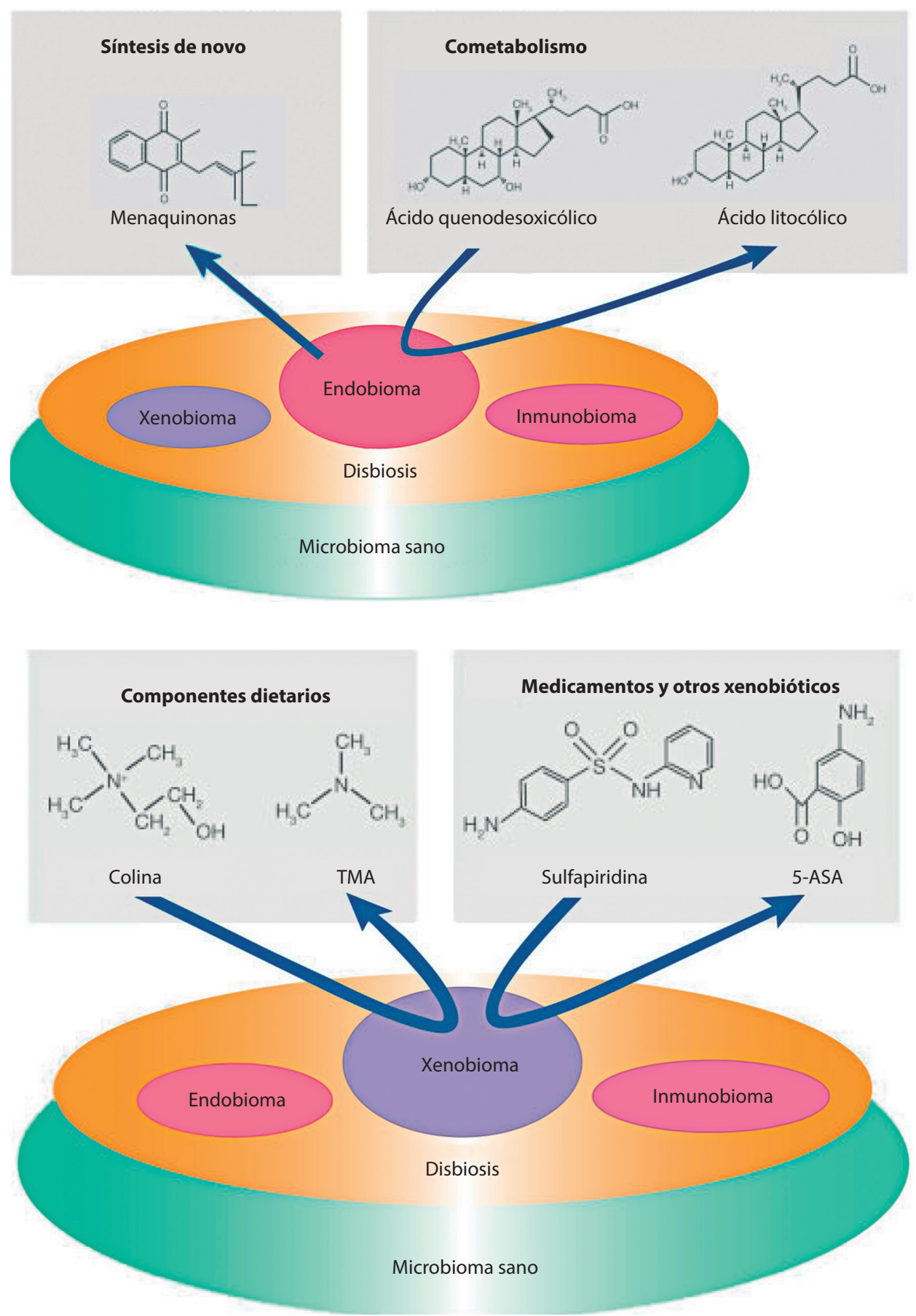

Figura 5. Metabolismo de la microbiota y su relación con la fisiología del huésped. Tomada y modificada de ${ }^{(21)}$.

Figura 6. Metabolismo de la microbiota y su relación con la fisiología del huésped. Tomada y modificada de ${ }^{(21)}$.

identificar la filogenia y catalogar taxonómicamente a la mayoría de los microorganismos, sin necesidad de cultivarlos $^{(14)}$. Particularmente, la secuenciación de la región V3-V4 del gen, que codifica la subunidad16S del ARNr (gen ADNr 16S), y las herramientas de análisis masivo de datos, proporcionan la información sobre la abundancia relativa de género en la mayoría de los casos (>90\%), pero menos con respecto a las especies (65\% a $83 \%)$, con $1 \%$ a $14 \%$ de aislamientos que quedan sin identificar después de la prueba. Existe una limitación para la identificación de nuevos taxones, por el poco número de secuencias depositadas en bases de 
datos de nucleótidos, especies que comparten secuencias de ARNr 16S similares o idénticas, o problemas de nomenclatura asignados a especies o complejos individuales (Figura 7) ${ }^{(22)}$.

\section{Influencia de los ácidos biliares en el control de la MI}

Se ha encontrado una estrecha relación de un proceso coevolutivo, que le ha costado a la humanidad alrededor de medio billón de años, en donde la dieta de nuestros ancestros, rica en polisacáridos y antioxidantes, ha forzado la evolución en la microbiota, haciéndolos capaces de extraer energía a partir de la alimentación, lo que permite una relación simbiótica a favor tanto del huésped como del hospedero ${ }^{(24)}$. Sin embargo, en años recientes, las ciudades industrializadas han llevado a un profundo cambio en los hábitos dietarios de la población en general, abandonando una dieta rica en cereales, frutas y vegetales, lo que permite el paso a una dieta occidentalizada, que se caracteriza por un alto contenido de proteínas animales y grasas saturadas ${ }^{(25)}$.

Esta dieta aumenta la secreción de ácidos biliares a la luz intestinal, lo que permite un incremento de la concentración de ácidos biliares hidrofóbicos, principalmente ácido quenodeoxicólico, del grupo total de ácidos biliares ${ }^{(26)}$ visto en modelos animales. Las dietas ricas en grasa disminuyen a los lactobacilos y aumentan los Clostridium subcluster XIVa, lo que permite un aumento en los niveles séricos de ácido deoxicólico. Esto ha demostrado un grado persistente de inflamación crónica y progresión tumoral ${ }^{(27)}$.

Asimismo, los ácidos biliares pueden tener repercusiones positivas y negativas en la $\mathrm{MI}^{(28)}$. Estos pueden ocasionar un efecto antimicrobiano de manera indirecta mediante el FXRa, el cual permite una regulación positiva de los genes involucrados en la línea de defensa innata, ubicados sobre la mucosa intestinal del íleon, entre los que se encuentran Ang1, iNos y IL18 ${ }^{(29)}$. En modelos animales se encontró que la ligadura del

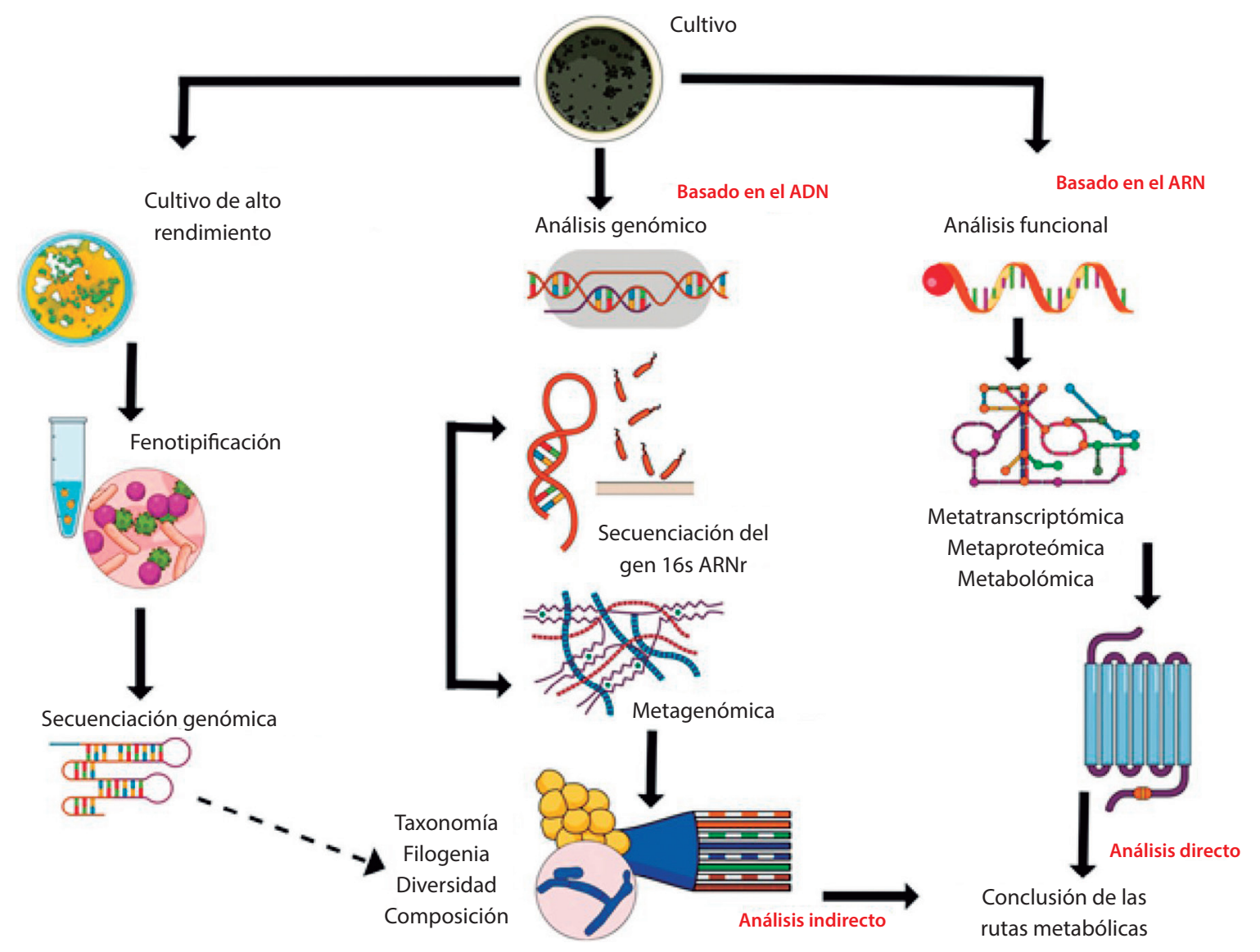

Figura 7. Diferentes métodos de estudios de la microbiota y del microbioma. Tomada y modificada de ${ }^{(23)}$. 
colédoco resultó en un sobrecrecimiento de bacterias aeróbicas y anaeróbicas en el íleon y en el ciego, lo que demostró que la activación del FXR $a$ puede prevenir la translocación bacteriana biliar ${ }^{29)}$.

En el enterocito, la activación del FXR $a$ estimula la producción de FGF15/19. Estas citocinas se unen al receptor FGFR4 sobre la superficie del hepatocito, lo cual inhibe la producción de colesterol $7 \alpha$-hidroxilasa (CYP7A1) y las síntesis de ácidos biliares ${ }^{(30)}$. Dicha activación también permite el accionamiento de la catelicidina, un péptido antimicrobiano que se encuentra en los ductos biliares ${ }^{(31)}$. Adicional, los ácidos biliares primarios también pueden promover la germinación de esporas, las cuales pueden estar presentes de manera no tóxica, además, pueden permitir la recuperación de la microbiota después de una disbiosis inducida por antibióticos o toxinas, el mejor ejemplo de esto es el Clostridium difficile ${ }^{(32)}$.

Por otra parte, muchos estudios han demostrado, de manera general, un impacto negativo de los ácidos biliares sobre la integridad de la membrana de la bacterias intestinales debido a un efecto detergente, lo que ocasiona una disminución en la producción de proteínas de membrana y un estrés oxidativo/nitrosativo ${ }^{(33)}$. Esto desencadena un aumento en su permeabilidad y muerte celular $^{(34)}$, siendo las bacterias Gram negativas más resistentes a los ácidos biliares que las Gram positivas ${ }^{(28)}$.

La extensión del daño celular se relaciona con la característica hidrofóbica y la estructura molecular de los ácidos biliares, por tanto, entre más hidrofóbico y mayor número de grupos hidroxi en su estructura, aumenta el efecto deletéreo sobre las membranas bacterianas. Además, estos son capaces de ocasionar un daño sobre el ADN, estimular el estrés oxidativo y quelar importantes iones celulares, como el calcio ${ }^{(28)}$.

\section{Influencia de la MI sobre los ácidos biliares}

Se ha demostrado una relación simbiótica entre la MI y el hígado, regulada y estabilizada por una red compleja de relaciones a nivel metabólico, inmune y neuroendocrino ${ }^{(35)}$. Las uniones estrechas entre las células de la mucosa intestinal representan una barrera natural contra las bacterias y sus productos metabólicos ${ }^{(17)}$. Las células dendríticas identifican los antígenos que pasan a través de estas conexiones, lo que permite la activación del sistema inmune adaptativo, que finalmente expresa una respuesta de las células $T$.

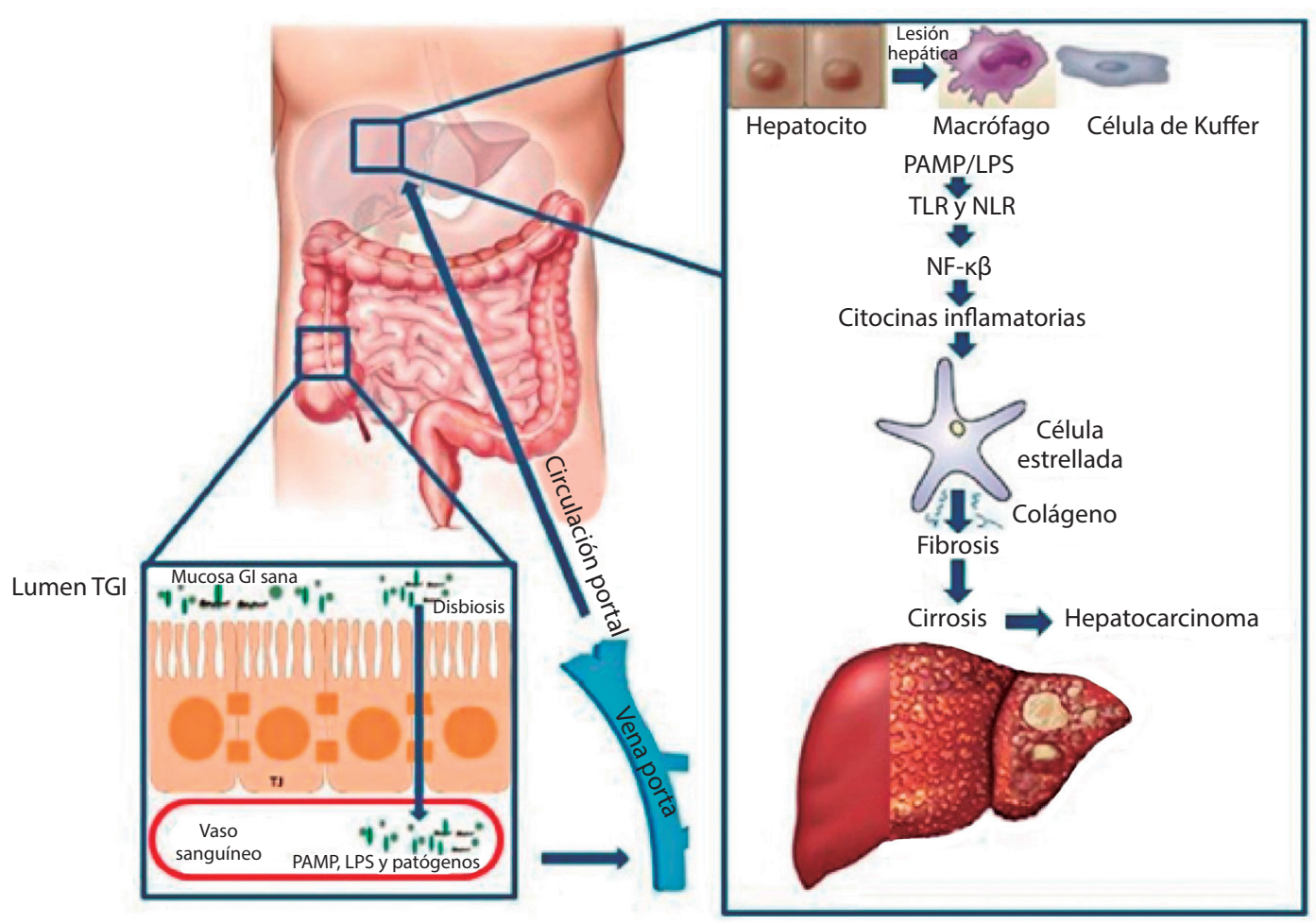

Figura 8. Patogénesis del eje intestino-hepático. Tomada y modificada de ${ }^{(17)}$. 
Concentraciones pequeñas de los productos moleculares asociados con patógenos (PAMP), como lipopolisacáridos, peptidoglicanos y flagelos, activan el factor nuclear kappa B (NF- $\kappa \beta)$, permiten la producción de citocinas proinflamatorias y quimiocinas, como la interleucina (IL) 1, IL-6 Y factor de necrosis tumoral alfa $(\mathrm{TNF}-\alpha)^{(23)}$, las cuales entran a la circulación portal y generan un proceso inflamatorio, que conlleva la producción de especies reactivas de oxígeno (ROS) (23) y a daños específicos a nivel funcional o estructural hepático (Figura 8$)^{(17)}$. También se ha encontrado una tolerancia específica por parte de los colangiocitos a lipopolisacáridos, a través de una vía de regulación denominada IRAK-M, la cual es una vía regulatoria negativa de los $\operatorname{TLR}^{(36)}$.

Dado que los ácidos biliares se transportan a través del intestino, estos son susceptibles a biotransformación por la MI. Se ha encontrado que esta principalmente se compone por Lactobacillus, Streptococcus, Staphylococcus y Veillonella, con concentraciones de $10^{3}$ a $10^{4}$ bacterias por $\mathrm{mL}$ en el duodeno y en el yeyuno; mientras que en el íleon se componen principalmente por Enterobacteria, Enterococcus, Bacteroides, Clostridium, Lactobacillus y Veillonella, en concentraciones mayores de $10^{6}$ a $10^{8}$ bacterias por $\mathrm{mL}^{(5)}$.

En conjunto, este grupo de bacterias es responsable de la conjugación de los ácidos biliares mediante hidrolasas y por oxidación de los grupos hidroxi ${ }^{(5)}$. Además, el crecimiento de bacterias, como Alistipes, Bilophila wadsworthia, Escherichia coli, Listeria monocytogenes y Bacteroides se facilita por los ácidos biliares, mientras que hay otras bacterias que pueden ser menos tolerantes a los ácidos biliares, como son los Lactobacillus, Bifidobacterium y Clostridium ${ }^{(27)}$.

La MI puede promover la secreción de enzimas en el intestino delgado, las cuales pueden afectar la síntesis de los ácidos biliares ${ }^{(37)}$, siendo la forma como se encuentra la hidrolasa de las sales biliares (BSH), principalmente en los Clostridium y Lactobacillus $^{(7)}$; estas últimas con una gran habilidad para remover el colesterol.

En el intestino, la glicina o taurina, unida al ácido cólico y deoxicólico, permite la biotransformación mediante la MI a ácidos biliares secundarios. En general, esta conjugación se realiza por bacterias anaerobias, mientras que la $7 a$ dehidroxilación de ácidos biliares ocurre por un número limitado de bacterias anaerobias. Así, los Bacteroides y Clostridium pueden metabolizar los ácidos biliares primarios y convertirlos en secundarios, lo que incrementa su hidrofobicidad, esto genera toxicidad y efectos secundarios metabólicos ${ }^{(38)}$.
La microbiota intestinal puede afectar los genes del FXR en el íleon. La activación del factor dependiente del FXR (FGF19) en el íleon regula la síntesis de los ácidos biliares en el hígado, pero la unión del FGF19 con el receptor 4 del factor de crecimiento fibroblástico (FGFR4) puede inhibir la síntesis de los ácidos biliares ${ }^{(7)}$.

\section{Transformación de los ácidos biliares}

La transformación de los ácidos biliares involucra diferentes procesos, entre ellos, la liberación de los ácidos biliares libres, la epimerización reversible entre las orientaciones $\alpha$ y $\beta$, y la oxidación de los grupos hidroxi 3,7 y $12^{(3)}$.

Los grupos hidroxi de los ácidos biliares, que se sintetizan en el hígado, tienen todos una orientación $\alpha$, lo que les da su característica anfipática, y permite una solubilización eficiente de moléculas lipídicas. Dicha conjugación y epimerización ocasiona una alteración en su patrón hidrofílico, lo que afecta la eficiencia de la solubilización lipídica o afinidad por la hidroxiesteroide deshidrogenasa. Así, la epimerización de los ácidos biliares por la MI y la acumulación de ácidos biliares, con orientación $\beta$ de los grupos hidroxi, le confiere un efecto protector al hígado al convertirlos en ácidos biliares hidrofóbicos ${ }^{(3)}$.

Los resultados de los estudios bioinformáticos y metagenómicos más recientes aclaran, de manera considerable, siendo aún limitado su identificación in vivo, la diversidad de microorganismos, que son capaces de alterar los ácidos biliares, y cómo su transformación puede modificar la $\mathrm{MI}^{(3)}$.

El primer paso para la modificación de los ácidos biliares incluye la conjugación mediante la BSH. Estas enzimas comparten un alto grado de similitud estructural con la penicilina $\mathrm{V}$ acilasa, proveniente del Bacillus sphaericus, distribuida de manera similar tanto en bacterias Gram negativas como Gram positivas de la $\mathrm{MI}^{(33)}$. Existen por lo menos 9 tipos de BSH. Estas difieren en tamaño, $\mathrm{pH}$, organización y regulación genética, lo que ha demostrado tener un papel preponderante en la colonización del intestino humano de patógenos como Listeria monocytogenes y Brucella abortus ${ }^{(39)}$, al igual que la detoxificación de los ácidos biliares mediante el barrido de carbono, nitrógeno y sulfuro ${ }^{(40)}$.

La hidroxiesteroide deshidrogenasa (HSD) es una enzima bacteriana, que actúa en la posición 3, 7 y 12 de los grupos hidroxi de los ácidos biliares. Dicha enzima modifica la característica hidrofóbica y tóxica de los ácidos biliares, y provee una fuente de energía para 
los procesos celulares ${ }^{(5)}$. Los análisis bioinformáticos han demostrado dos diferentes clases de $3 \alpha$-HSD en la Comamonas testosteroni ${ }^{(41)}$ y homólogos de la forma $3 \alpha$-HSD encontrados en el filo de los Firmicutes.

\section{Relación entre los ácidos biliares y la microbiota, y su asociación con las colangiopatías}

El árbol biliar se compone por una red tridimensional de conductos, que drenan la bilis a la luz intestinal. Está compuesto por células epiteliales lineales denominadas colangiocitos $^{(42)}$, que se ubican en el borde luminal de los conductos biliares, tanto a nivel intra como extrahepático. En condiciones normales, este permite el transporte de la bilis, la cual es estéril en la mayoría de los casos; sin embargo, en hepatopatías se han detectado PAMP, como lipopolisacáridos, ácido lipoteicoico y fragmentos de $\mathrm{ADN}$ bacteriano ${ }^{(43)}$, lo que le permite a estos colangiocitos expresar una cantidad de receptores de la inmunidad innata ${ }^{(44)}$, entre los que se incluyen los TLR, principalmente tipo 4, los cuales permiten la secreción de IL-6, IL-8 mediante las vías de señalización NF-к $\beta$ y MAPK, papel preponderante a este tipo de receptores en la fisiopatología de las colangiopatías ${ }^{(36)}$.

Los colangiocitos se dividen en células pequeñas y grandes, dependiendo de su ubicación en los conductos biliares. De este modo, los colangiocitos ubicados en las vías biliares de gran tamaño participan activamente en la modificación de la composición biliar y de su volumen, a través de mecanismos de absorción y secretores regulados por diferentes moléculas, entre las que se incluyen hormonas, péptidos y neurotransmisores ${ }^{(45)}$; mientras que los pequeños colangiocitos son capaces de modificar su fenotipo en respuesta a estímulos dañinos tanto exógenos como endógenos, además de su participación activa durante procesos inflamatorios ${ }^{(46)}$.

Los colangiocitos son el blanco de un grupo de enfermedades conocidas como colangiopatías, las cuales pueden tener diferentes etiologías, entre las que se incluyen genéticas, autoinmunes, infecciosas, tóxicas, idiopáticas, entre otras ${ }^{(46)}$. Así, en respuesta a la noxa, los colangiocitos que se encuentran en estado quiescente inician una proliferación y liberación de mediadores, a través de los cuales pueden interactuar con células a nivel hepático residentes y no residentes, lo que mantiene la homeostasis y su funcionalidad ${ }^{(46)}$.

Como hemos visto, las alteraciones, tanto en la composición como en la homeostasis de los ácidos biliares asociados con la disrupción de la MI, ocasionan un proceso inflamatorio crónico sobre los colangiocitos, el cual se ha considerado como un factor etiológico en diferentes colangiopatías, motivo por el cual se revisa la relación entre los ácidos biliares, la microbiota y su asociación con algunos tipos de colangiopatías.

\section{COLANGITIS ESCLEROSANTE PRIMARIA (CEP)}

Se reconoce la fuerte asociación entre la CEP y la enfermedad inflamatoria intestinal, siendo una enfermedad hepática colestática crónica, caracterizada por la destrucción de los conductos biliares. Esto puede ocurrir en presencia, o no, de la enfermedad inflamatoria intestinal, y se ha asociado con factores genéticos y con factores de riesgo ambiental ${ }^{(47)}$.

Como factor etiológico, la microbiota se ha aceptado ampliamente, aunque la patogénesis no se ha entendido completamente. Generalmente se asume que el proceso inflamatorio crónico se da por una respuesta inmune aberrante frente a antígenos de la MI, residente en individuos genéticamente susceptibles ${ }^{(48)}$.

\section{Inmunobioma del CEP}

La hipótesis clásica sugiere que los productos bacterianos presentan translocación en el intestino, lo que causa inflamación a nivel de la vía biliar; sin embargo, este concepto solo se ha probado en modelos animales, pues en humanos la evidencia es limitada ${ }^{(49)}$. Con esto se demuestra un incremento en la expresión de TLR4 y una respuesta exagerada a los lipopolisacáridos bacterianos (LPS) a nivel de los colangiocitos ${ }^{(50)}$. A pesar de esto, otros estudios de biomarcadores que miden la permeabilidad intestinal muestran resultados contradictorios.

Por lo anterior, se ha sugerido que existirían tres mecanismos responsables de la CEP: el primero asociado con una respuesta inmunológica directa a nivel de los colangiocitos; el segundo relacionado con una respuesta inmunológica cruzada mediante mimetismo molecular, como se ha demostrado en otras patologías, como algunas glomerulopatía ${ }^{(51)}$; y el tercero mediante una respuesta reguladora sobreexpresada, como sucede en patologías autoinmunes ${ }^{(52)}$.

\section{Endobioma en la CEP}

La colestasis es el factor clave para un diagnóstico; sin embargo, para llegar a este debe existir una alteración inicial en la composición de la bilis y en los mecanismos protectores, descritos de manera previa ${ }^{(53)}$. Dichas 
modificaciones alteran, como fin último, el FXR, lo que limita la síntesis de los ácidos biliares a expensas del colesterol, específicamente mediante el colesterol 7 $\alpha$-hidroxilasa (CYP7A1).

\section{Xenobioma en la CEP}

También conocido como exposoma, así la MI depende, entre otros, de factores nutricionales y de la exposición oral del ambiente ${ }^{(26)}$. De esta manera, los macronutrientes, especialmente las fibras no digeribles, generan ácidos grasos de cadena corta, entre los que se incluye el acetato, propionato y butirato, los cuales actúan unidos a los receptores acoplados a la proteína G, GPR41 y GPR43 en el intestino, esto permite la activación de las vías proinflamatorias y endocrinas ${ }^{(54)}$. Estos además sirven como nutrientes a la barrera epitelial sobre el tracto gastrointestinal, y pueden estimular el acúmulo de células $\mathrm{T}$ reguladoras, lo que podría producir un efecto terapéutico sobre la desregulación de la microbiota, esto puede ser uno de los mecanismos efectores en el trasplante de la materia fecal ${ }^{(55)}$.

De otra manera, la modificación de enzimas por parte de la MI puede ser una explicación adecuada a la CEP, así es como a través de esta existe una formación de trimetilamina (TMA) desde colina. Los alimentos fuentes de fosfatidilcolina, como las carnes rojas y los queso, aumentan la formación de trimetilamina-Noxido (TMAO) desde la TMA en el hígado, el cual se ha asociado con la progresión de CEP a expensas de un proceso inflamatorio crónico ${ }^{(56)}$.

La inflamación y obstrucción del conducto biliar resulta en una alteración del flujo biliar y una disminución en la resistencia a la toxicidad de los ácidos biliares. El rol de la MI en la progresión de la enfermedad se empezó a reconocer mediante un estudio que usaba como tratamiento el ácido ursodesoxicólico frente al ácido ursodesoxicólico más metronidazol, por lo que se encontró que mientras la terapia única mejoraba la bioquímica, el uso del metronidazol no afectaba los resultados clínicos ${ }^{(57)}$.

En otro estudio se encontró la enfermedad hepática como factor primario, lo que ocasionaba una desregulación en la secreción de los ácidos biliares y una alteración en la MI, lo que logra identificar las bacterias tanto a nivel de género como de especies ${ }^{(58)}$. El género Adlercreutzia se encuentra disminuido en los pacientes con CEP. Este es capaz de convertir las isoflavonas ingeridas, las cuales son abundantes en leguminosas, especialmente la soja, por su isoflavona equol reco- nocida ${ }^{(59)}$. Esta última tiene una alta afinidad por los receptores estrogénicos, convirtiéndose en un modulador de dichos receptores. Así, una sobreexpresión de receptores estrogénicos sobre el colangiocitos puede aumentar la colestasis en pacientes con compromiso hepático, pero no en pacientes sanos ${ }^{(60)}$. En otros estudios se ha encontrado un aumento significativo del género Veillonella ${ }^{(61)}$, el cual también se ha asociado con otras enfermedades inflamatorias crónicas clínicas ${ }^{(62)}$.

Otro estudio encontró un incremento en Blautia y Barnesiellaceae ${ }^{(63)}$. Ciertas especies Blautia pueden llevar a cabo la dehidroxilación de ácidos biliares primarios, un proceso necesario para ser convertidos en secundarios, por lo que es más frecuente encontrar un aumento de ácidos biliares, secundarios en la materia fecal de pacientes con CEP. Además, se encontró que las concentraciones de los ácidos biliares primarios tenían una correlación positiva $(p<0,05)$, con una cantidad abundante de Blautia, tal y como se detalla en la Figura $9^{(64)}$.

Por el contrario, Torres y colaboradores encontraron un aumento no significativo de Ruminococcus y Fusobacterium, y una disminución en las bacterias del gen Dorea, Veillonella, Lachnospira, Blautia y Roseburia, contrario a lo encontrado por los otros grupos, aunque se halló un aumento en la Veillonella en pacientes con una enfermedad más severa, y con poca respuesta al ácido ursodesoxicólico ${ }^{(65)}$, lo que se podría explicar por el grado de inflamación, ocasionado por esta última ${ }^{(66)}$.

Algunos estudios prospectivos han explorado los efectos antimicrobianos de los antibióticos, sumados al ácido ursodesoxicólico, entre los que se encuentra el metronidazol, la minociclina, la vancomicina o la rifaximina. La observación general demostró que existe una mejoría en la bioquímica, lo que permitiría su uso como biomarcadores, sin una mejoría histológica de la CEP y sí un aumento en los efectos secundarios de los medicamentos. En cuanto al trasplante de materia fecal no existen estudios que permitan dar una recomendación al respecto ${ }^{(21)}$.

La posibilidad de que la MI pueda ser el origen de anticuerpos específicos causantes de CEP se apoya solo en evidencia circunstancial. Estudios genéticos en enfermedades autoinmunes han determinado también la importancia del antígeno leucocitario humano (HLA). En el caso de CEP se identificó mayor susceptibilidad al tipo HLA B 08 y DRB1 03.

Se requieren más estudios para aclarar el papel de la microbiota intestinal y su relación con los ácidos biliares en esta patología. Además, se podrían determinar bio- 


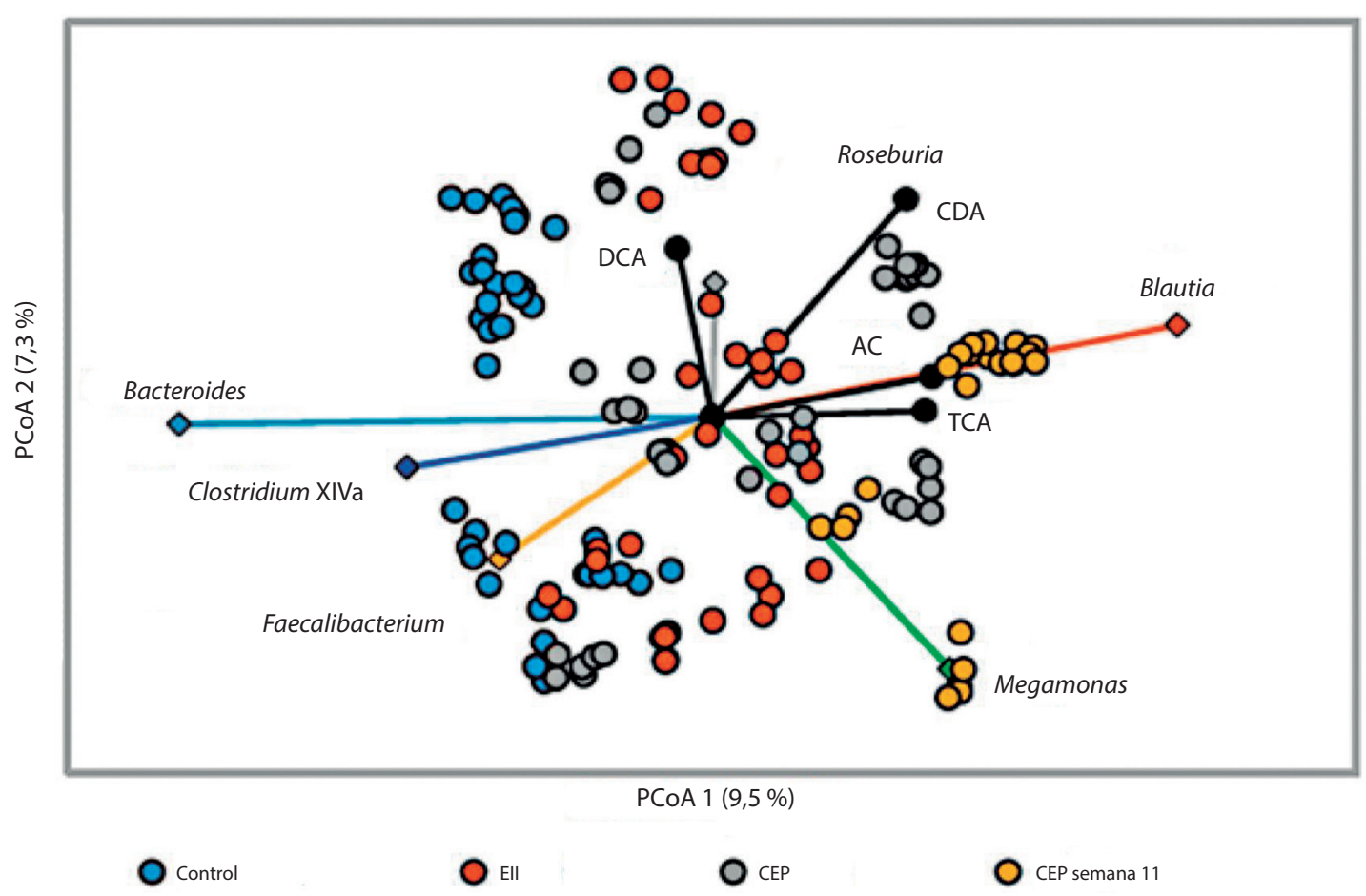

Figura 9. Correlación entre la microbiota y los ácidos biliares fecales. AC: ácido cólico; CDA: ácido quenodeoxicólico; CEP: colangitis esclerosante primaria; DCA: ácido deoxicólico; Ell: enfermedad inflamatoria intestinal; TCA: ácido taurocólico. Tomada y modificada de ${ }^{(64)}$.

marcadores para una detección temprana y control de la enfermedad. Se han realizado estudios de manejo, como el uso de vancomicina y el trasplante fecal, aunque los resultados aún continúan siendo contradictorios ${ }^{(56)}$.

\section{COLANGIOCARCINOMA}

El colangiocarcinoma es el cáncer de la vía biliar, el cual se puede clasificar como intrahepático, hiliar y extrahepático, dependiendo de su ubicación anatómica. Entre los principales factores de riesgo se encuentra la CEP y los procesos obstructivos crónicos clínicos ${ }^{(67)}$.

Estudios epidemiológicos han demostrado una relación de cánceres hepatobiliares, con infecciones de la especie Helicobacter, entre las que se incluye el Helicobacter pylori, Helicobacter bilis y Helicobacter hepaticus ${ }^{(68,69)}$. De este modo, estudios experimentales han demostrado que el Helicobacter bilis puede activar las vías de señalización NF- $\kappa \beta$ e incrementar la producción del factor de crecimiento endotelial vascular (VEGF), lo que ha demostrado una angiogénesis significativa en lesiones tumorales del árbol biliar ${ }^{(70)}$.

En estudios clínicos, en que se usan análisis metagenómicos, se ha demostrado que las bacterias de la familias Bifidobacteriaceae, Enterobacteriaceae y
Enterococcaceae se relacionan con la presencia del Opisthorchis viverrini, un parasito asociado con la colangiocarcinoma, principalmente en el sudeste asiático ${ }^{(71)}$. También se ha encontrado un aumento significativo de especies como Methylophilaceae, Fusobacterium, Prevotella, Actinomyces, Novosphingobium y Helicobacter pylori en colangiocarcinoma distales clínicos ${ }^{(72)}$.

En el colangiocarcinoma intrahepático se encontró una alta prevalencia de Lactobacillus, Actinomyces, Peptostreptococcaceae y Alloscardovia ${ }^{(49)}$; además de un incremento en sangre de niveles de ácido glicoquenodesoxicólico, ácido glicodeoxicólico, ácido glicoursodesoxicólico, ácido tricarboxílico, ácido taurodoxicólico y ácido taurodeoxicólico, al igual que de IL-4, con una disminución en el plasma de ácido quenodeoxicólico y de IL-6. Los ácidos biliares libres (por ejemplo, CA, DCA y CDCA) inhiben el crecimiento de las células tumorales al estimular la apoptosis y disminuir la expresión de IL-6 ${ }^{(49)}$.

\section{CÁNCER DE VESÍCULA BILIAR}

El cáncer de vesícula es el más prevalente de los cánceres del tracto biliar ${ }^{(73)}$. El principal factor de riesgo es la inflamación crónica de la vesícula biliar, además, 
se encuentra la presencia de cálculos, obesidad, factores hormonales, exposición ambiental a mutágenos específicos y predisposición genética ${ }^{(74)}$. Se ha demostrado asociación con infecciones crónica de Salmonella typhi ${ }^{(75)}$, H. bilis, H. hepaticus y E. coli ${ }^{(76)}$.

Específicamente, la Salmonella enterica serovar Typhi es la causante de la fiebre tifoidea, y tiene la habilidad de causar una infección crónica asintomática en un pequeño porcentaje de los pacientes $(2 \%-3 \%)$ con infecciones agudas ${ }^{(66)}$. Esta infección se asocia con la presencia de cálculos biliares, lo que facilita la colonización de la bilis por estas bacterias, esto permite una inactivación del TP53 y amplificación del MYC a través de las vías de señalización $\operatorname{MAPK}^{(77,78)}$. Además, la glucuronidasa bacteriana produce un metabolito altamente energético, que transforma la bilis en un potente carcinogénico, sumado a un aumento en las concentraciones de ácidos biliares secundarios, los cuales son conocidos como promotores tumorales, secundario a un estado proinflamatorio crónico, como fisiopatología cancerigenita $^{(76)}$.

En un estudio de pacientes bolivianos y chilenos con cáncer de vesícula se identificó el F. nucleatum, E. coli y Enterobacter, como especies presentes y causantes de este tipo de cáncer, pero no se identificaron especies de Salmonella ${ }^{(79)}$.

Las especies de Helicobacter son organismos resistentes a los ácidos biliares, además de la producción de ureasa propias de estas bacterias, lo que ocasiona una infección y un estado proinflamatorio crónico ${ }^{(80)}$; sin embargo, aún se requieren estudios adicionales para aclarar la forma en cómo estas bacterias se relacionan con el cáncer de vesícula ${ }^{(76)}$.

\section{CONCLUSIONES}

La evidencia muestra diferentes vías implicadas en la producción y metabolismo de los ácidos biliares, y su estrecha relación con la MI, lo que permite modificaciones duales frente a las alteraciones en la homeostasis en la composición de la MI mediante la modificación en la abundancia relativa de los principales filos identificados y diversidad de microorganismos con implicaciones específicas, y en el metabolismo de los ácidos biliares, lo que desencadena reacciones inflamatorias crónicas, que pueden explicar diversas patologías definidas como idiosincráticas en los colangiocitos.

Aunque el estudio de la MI, aún incipiente como factor etiológico, se ha enfocado principalmente en enfermedades de tipo inflamatorio, infeccioso y metabólico, como la esteatohepatitis no alcohólica (NASH), se puede observar cómo se logra relacionar con diferentes patologías en las que nos vemos inmersos diariamente. Es así como en esta revisión realizamos una aproximación a la evidencia en otro tipo de patologías, lo cual abre la puerta a nuevas investigaciones en el tema, que permitan aclarar el papel de la MI en las modificaciones estructurales y funcionales de los ácidos biliares, y su relación con la fisiopatología de los colangiocitos.

\section{Referencias bibliográficas}

1. Kriaa A, Bourgin M, Potiron A, Mkaouar H, Jablaoui A, Gérard P, et al. Microbial impact on cholesterol and bile acid metabolism: Current status and future prospects. J Lipid Res. 2019;60(2):323-32. doi: 10.1194/jlr.R088989.

2. Chiang JYL. Bile acids: Regulation of synthesis. J Lipid Res. 2009;50(10):1955-66. doi: 10.1194/jlr.R900010-JLR200.

3. Staley C, Weingarden AR, Khoruts A, Sadowsky MJ. Interaction of gut microbiota with bile acid metabolism and its influence on disease states. Appl Microbiol Biotechnol. 2017;101(1):47-64. doi: 10.1007/s00253-016-8006-6.

4. Chiang JYL. Regulation of bile acid synthesis: Pathways, nuclear receptors, and mechanisms. J Hepatol. 2004;40(3):539-51. doi: 10.1016/j.jhep.2003.11.006.

5. Ridlon JM, Kang DJ, Hylemon PB. Bile salt biotransformations by human intestinal bacteria. J Lipid Res. 2006;47(2):241-59. doi: 10.1194/jlr.R500013-JLR200.

6. Hofmann AF. The continuing importance of bile acids in liver and intestinal disease. Arch Intern Med. 1999;159(22):264758. doi: 10.1001/archinte.159.22.2647.

7. Jia E, Liu Z, Pan M, Lu J, Ge Q. Regulation of bile acid metabolism-related signaling pathways by gut microbiota in diseases. J Zhejiang Univ Sci B. 2019;20(10):781-92. doi: 10.1631/ jzus.B1900073.

8. Edwards PA, Kast HR, Anisfeld AM. BAREing it all: The adoption of LXR and FXR and their roles in lipid homeostasis. J Lipid Res. 2002;43(1):2-12.

9. Kim I, Ahn SH, Inagaki T, Choi M, Ito S, Guo GL, et al. Differential regulation of bile acid homeostasis by the farnesoid $\mathrm{X}$ receptor in liver and intestine. J Lipid Res. 2007;48(12):2664-72. doi: 10.1194/jlr.M700330-JLR200.

10. Dossa AY, Escobar O, Golden J, Frey MR, Ford HR, Gayer CP. Bile acids regulate intestinal cell proliferation by modulating EGFR and FXR signaling. Am J Physiol Gastrointest Liver Physiol. 2016;310(2):G81-92. doi: 10.1152/ ajpgi.00065.2015.

11. Sayin SI, Wahlström A, Felin J, Jäntti S, Marschall HU, Bamberg $\mathrm{K}$, et al. Gut microbiota regulates bile acid metabolism by reducing the levels of tauro-beta-muricholic acid, a naturally occurring FXR antagonist. Cell Metab. 2013;17(2):225-35. doi: 10.1016/j.cmet.2013.01.003. 
12. Hu X, Bonde Y, Eggertsen G, Rudling M. Muricholic bile acids are potent regulators of bile acid synthesis via a positive feedback mechanism. J Intern Med. 2014;275(1):27-38. doi: 10.1111/joim.12140.

13. Hylemon PB, Zhou H, Pandak WM, Ren S, Gil G, Dent P. Bile acids as regulatory molecules. J Lipid Res. 2009;50(8):150920. doi: 10.1194/jlr.R900007-JLR200.

14. del Campo-Moreno R, Alarcón-Cavero T, D’Auria G, Delgado-Palacio S, Ferrer-Martínez M. Microbiota en la salud humana: técnicas de caracterización y transferencia. Enferm Infecc Microbiol Clin. 2018;36(4):241-5. doi: 10.1016/j. eimc.2017.02.007.

15. D'Argenio V, Salvatore F. The role of the gut microbiome in the healthy adult status. Clin Chim Acta. 2015;451(A):97102. doi: 10.1016/j.cca.2015.01.003.

16. Dethlefsen L, McFall-Ngai M, Relman DA. An ecological and evolutionary perspective on human-microbe mutualism and disease. Nature. 2007;449(7164):811-8. doi: 10.1038/ nature06245.

17. Milosevic I, Vujovic A, Barac A, Djelic M, Korac M, Spurnic $\mathrm{AR}$, et al. Gut-liver axis, gut microbiota, and its modulation in the management of liver diseases: A review of the literature. Int J Mol Sci. 2019;20(2):395. doi: 10.3390/ijms20020395.

18. Kummen M, Vesterhus M, Trøseid M, Moum B, Svardal A, Boberg $\mathrm{KM}$, et al. Elevated trimethylamine- $\mathrm{N}$-oxide (TMAO) is associated with poor prognosis in primary sclerosing cholangitis patients with normal liver function. United European Gastroenterol J. 2017;5(4):532-41. doi: $10.1177 / 2050640616663453$.

19. O'Hara AM, Shanahan F. The gut flora as a forgotten organ. EMBO Rep. 2006;7(7):688-93. doi: 10.1038/ sj.embor.7400731.

20. Quigley EM, Monsour HP. The gut microbiota and the liver: Implications for clinical practice. Expert Rev Gastroenterol Hepatol. 2013;7(8):723-32. doi: 10.1586/17474124.2013.848167.

21. Hov JR, Karlsen TH. The microbiome in primary sclerosing cholangitis: Current evidence and potential concepts. Semin Liver Dis. 2017;37(4):314-31. doi: 10.1055/s-00371608801.

22. Janda JM, Abbott SL. 16S rRNA gene sequencing for bacterial identification in the diagnostic laboratory: Pluses, perils, and pitfalls. J Clin Microbiol. 2007;45(9):2761-4. doi: 10.1128/ JCM.01228-07.

23. Philips CA, Augustine P, Yerol PK, Ramesh GN, Ahamed $\mathrm{R}$, Rajesh S, et al. Modulating the intestinal microbiota: Therapeutic opportunities in liver disease. J Clin Transl Hepatol.2020;8(1):87-99. doi: 10.14218/JCTH.2019.00035.

24. Martens EC, Lowe EC, Chiang H, Pudlo NA, Wu M, McNulty $\mathrm{NP}$, et al. Recognition and degradation of plant cell wall polysaccharides by two human gut symbionts. PLoS Biol. 2011;9(12). doi: 10.1371/journal.pbio.1001221.
25. Gutiérrez-Díaz I, Molinero N, Cabrera A, Rodríguez JI, Margolles A, Delgado S, et al. Diet: Cause or consequence of the microbial profile of cholelithiasis disease? Nutrients. 2018;10(9):1307. doi: 10.3390/nu10091307.

26. David LA, Maurice CF, Carmody RN, Gootenberg DB, Button JE, Wolfe BE, et al. Diet rapidly and reproducibly alters the human gut microbiome. Nature. 2014;505(7484):559-63. doi: $10.1038 /$ nature 12820 .

27. DiCiaula A, Garruti G,Baccetto RL, Molina-MolinaE, Bonfrate L, Wang DQ-H, et al. Bile acid physiology. Ann Hepatol. 2017;16(1):s4-s14. doi: 10.5604/01.3001.0010.5493.

28. Begley M, Sleator RD, Gahan CGM, Hill C. Contribution of three bile-associated loci, bsh, pva, and btlB, to gastrointestinal persistence and bile tolerance of Listeria monocytogenes. Infect Immun. 2005;73(2):894-904. doi: 10.1128/ IAI.73.2.894-904.2005.

29. Inagaki T, Moschetta A, Lee YK, Peng L, Zhao G, Downes M, et al. Regulation of antibacterial defense in the small intestine by the nuclear bile acid receptor. Proc Natl Acad Sci USA. 2006;103(10):3920-5. doi: 10.1073/pnas.0509592103.

30. Cahova M, Bratova M, Wohl P. Parenteral nutrition-associated liver disease: The role of the gut microbiota. Nutrients. 2017;9(9):987. doi: 10.3390/nu9090987.

31. D’Aldebert E, Biyeyeme BMJ, Mergey M, Wendum D, Firrincieli D, Coilly A, et al. Bile salts control the antimicrobial peptide cathelicidin through nuclear receptors in the human biliary epithelium. Gastroenterology. 2009;136(4):1435-43. doi: 10.1053/j.gastro.2008.12.040.

32. Lavelle A, Sokol H. Gut microbiota-derived metabolites as key actors in inflammatory bowel disease. Nat Rev Gastroenterol Hepatol. 2020;17(4):223-37. doi: 10.1038/s41575-0190258-z.

33. Jones BV, Begley M, Hill C, Gahan CGM, Marchesi JR. Functional and comparative metagenomic analysis of bile salt hydrolase activity in the human gut microbiome. Proc Natl Acad Sci USA. 2008;105(36):13580-5. doi: 10.1073/ pnas.0804437105.

34. De Boever P, Wouters R, Verschaeve L, Berckmans P, Schoeters G, Verstraete W. Protective effect of the bile salt hydrolase-active Lactobacillus renteri against bile salt cytotoxicity. Appl Microbiol Biotechnol. 2000;53(6):709-14. doi: $10.1007 / \mathrm{s} 002530000330$.

35. Kho ZY, Lal SK. The human gut microbiome - A potential controller of wellness and disease. Front Microbiol. 2018;9:1835. doi: 10.3389/fmicb.2018.01835.

36. Maroni L, Ninfole E, Pinto C, Benedetti A, Marzioni M. Gut-liver axis and inflammasome activation in cholangiocyte pathophysiology. Cells. 2020;9(3):736. doi: 10.3390/ cells9030736.

37. Mullish BH, Pechlivanis A, Barker GF, Thursz MR, Marchesi JR, McDonald JAK. Functional microbiomics: Evaluation of gut microbiota-bile acid metabolism interactions in health and disease. Methods. 2018;149:49-58. doi: 10.1016/j. ymeth.2018.04.028. 
38. Jia W, Xie G, Jia W. Bile acid-microbiota crosstalk in gastrointestinal inflammation and carcinogenesis. Nat Rev Gastroenterol Hepatol. 2018;15(2):111-28. doi: 10.1038/ nrgastro.2017.119.

39. Delpino MV, Marchesini MI, Estein SM, Comerci DJ, Cassataro J, Fossati CA, et al. A bile salt hydrolase of Brucella abortus contributes to the establishment of a successful infection through the oral route in mice. Infect Immun. 2007;75(1):299-305. doi: 10.1128/IAI.00952-06.

40. Tanaka H, Hashiba H, Kok J, Mierau I. Bile salt hydrolase of Bifidobacterium longum - Biochemical and genetic characterization. Appl Environ Microbiol. 2000;66(6):2502-12. doi: 10.1128/aem.66.6.2502-2512.2000.

41. Kisiela M, Skarka A, Ebert B, Maser E. Hydroxysteroid dehydrogenases (HSDs) in bacteria: A bioinformatic perspective. J Steroid Biochem Mol Biol. 2012;129(1-2):31-46. doi: 10.1016/j.jsbmb.2011.08.002.

42. Yoo KS, Lim WT, Choi HS. Biology of cholangiocytes: From bench to bedside. Gut Liver. 2016;10(5):687-98. doi: $10.5009 /$ gnl16033.

43. Hiramatsu K, Harada K, Tsuneyama K, Sasaki M, Fujita S, Hashimoto $\mathrm{T}$, et al. Amplification and sequence analysis of partial bacterial $16 \mathrm{~S}$ ribosomal RNA gene in gallbladder bile from patients with primary biliary cirrhosis. J Hepatol. 2000;33(1):9-18. doi: 10.1016/s0168-8278(00)80153-1.

44. Giudicessi JR, Ackerman MJ. Determinants of incomplete penetrance and variable expressivity in heritable cardiac arrhythmia syndromes. Transl Res. 2013;161(1):1-14. doi: 10.1016/j.trs1.2012.08.005.

45. Maroni L, Haibo B, Ray D, Zhou T, Wan Y, Meng F, et al. Functional and structural features of cholangiocytes in health and disease. Cell Mol Gastroenterol Hepatol. 2015; 1(4):36880. doi: 10.1016/j.jcmgh.2015.05.005.

46. Giordano DM, Pinto C, Maroni L, Benedetti A, Marzioni M. Inflammation and the gut-liver axis in the pathophysiology of cholangiopathies. Int J Mol Sci. 2018;19(10):3003. doi: 10.3390/ijms19103003.

47. DysonJK, Beuers U,Jones DEJ,Lohse AW, Hudson M.Primary sclerosing cholangitis. Lancet. 2018;391(10139):2547-59. doi: 10.1016/S0140-6736(18)30300-3.

48. Sartor RB. Microbial influences in inflammatory bowel diseases. Gastroenterology. 2008;134(2):577-94. doi: 10.1053/j. gastro.2007.11.059.

49. Jia X, Lu S, Zeng Z, Liu Q, Dong Z, Chen Y, et al. Characterization of gut microbiota, bile acid metabolism, and cytokines in intrahepatic cholangiocarcinoma. Hepatology. 2020;71(3):893-906. doi: 10.1002/hep.30852.

50. Mueller T, Beutler C, Picó AH, Shibolet O, Pratt DS, Pascher A, et al. Enhanced innate immune responsiveness and intolerance to intestinal endotoxins in human biliary epithelial cells contributes to chronic cholangitis. Liver Int. 2011;31(10):157488. doi: 10.1111/j.1478-3231.2011.02635.x.
51. Zhang X, Zhang D, Jia H, Feng Q, Wang D, Liang D, et al. The oral and gut microbiomes are perturbed in rheumatoid arthritis and partly normalized after treatment. Nat Med. 2015;21(8):895-905. doi: 10.1038/nm.3914.

52. Hov JR, Boberg KM, Taraldsrud E, Vesterhus M, Boyadzhieva M, Solberg IC, et al. Antineutrophil antibodies define clinical and genetic subgroups in primary sclerosing cholangitis. Liver Int. 2017;37(3):458-65. doi: 10.1111/liv.13238.

53. Hohenester S, de Buy WLM, Paulusma CC, van Vliet SJ, Jefferson DM, Oude Elferink RP, et al. A biliary HCO 3-umbrella constitutes a protective mechanism against bile acid-induced injury in human cholangiocytes. Hepatology. 2012;55(1):173-83. doi: 10.1002/hep.24691.

54. Rooks MG, Garrett WS. Gut microbiota, metabolites and host immunity. Nat Rev Immunol. 2016;16(6):341-52. doi: 10.1038/nri.2016.42.

55. Rossen NG, Fuentes S, van Der Spek MJ, Tijssen JG, Hartman JHA, Duflou A, et al. Findings from a randomized controlled trial of fecal transplantation for patients with ulcerative colitis. Gastroenterology. 2015;149(1):110-118.e4. doi: 10.1053/j. gastro.2015.03.045.

56. Hov JR, Kummen M. Intestinal microbiota in primary sclerosing cholangitis. Curr Opin Gastroenterol. 2017;33(2):85-92. doi: 10.1097/MOG.0000000000000334.

57. Färkkilä M, Karvonen AL, Nurmi H, Nuutinen H, Taavitsainen M, Pikkarainen P, et al. Metronidazole and ursodeoxycholic acid for primary sclerosing cholangitis: A randomized placebo-controlled trial. Hepatology. 2004;40(6):1379-86. doi: 10.1002/hep.20457.

58. Bajer L, Kverka M, Kostovcik M, Macinga P, Dvorak J, Stehlikova Z, et al. Distinct gut microbiota profiles in patients with primary sclerosing cholangitis and ulcerative colitis. World J Gastroenterol. 2017;23(25):4548-58. doi: 10.3748/ wjg.v23.i25.4548.

59. Maruo T, Sakamoto M, Ito C, Toda T, Benno Y. Adlercreutzia equolifaciens gen. nov., sp. nov., an equol-producing bacterium isolated from human faeces, and emended description of the genus Eggerthella. Int J Syst Evol Microbiol. 2008;58(5):1221-7. doi: 10.1099/ijs.0.65404-0.

60. Alvaro D, Invernizzi P, Onori P, Franchitto A, De Santis A, Crosignani A, et al. Estrogen receptors in cholangiocytes and the progression of primary biliary cirrhosis. J Hepatol. 2004;41(6):905-12. doi: 10.1016/j.jhep.2004.08.022.

61. Sabino J, Vieira-Silva S, Machiels K, Joossens M, Falony G, Ballet V, et al. Primary sclerosing cholangitis is characterised by intestinal dysbiosis independent from IBD. Gut. 2016;65(10):1681-9. doi: 10.1136/gutjnl-2015-311004.

62. Tilg H, Cani PD, Mayer EA. Gut microbiome and liver diseases. Gut. 2016;65(12):2035-44. doi: 10.1136/ gutjnl-2016-312729.

63. Torres J, Bao X, Goel A, Colombel JF, Pekow J, Jabri B, et al. The features of mucosa-associated microbiota in primary scle- 
rosing cholangitis. Aliment Pharmacol Ther. 2016;43(7):790801. doi: 10.1111/apt.13552.

64. Vaughn BP, Kaiser T, Staley C, Hamilton MJ, Reich J, Graiziger $\mathrm{C}$, et al. A pilot study of fecal bile acid and microbiota profiles in inflammatory bowel disease and primary sclerosing cholangitis. Clin Exp Gastroenterol. 2019;12:9-19. doi: 10.2147/ CEG.S186097.

65. Tang R, Wei Y, Li Y, Chen W, Chen H, Wang Q et al. Gut microbial profile is altered in primary biliary cholangitis and partially restored after UDCA therapy. Gut. 2018;67(3):53441. doi: 10.1136/gutjnl-2016-313332.

66. Torres J, Palmela C, Brito H, Bao X, Ruiqi H, Moura-Santos $\mathrm{P}$, et al. The gut microbiota, bile acids and their correlation in primary sclerosing cholangitis associated with inflammatory bowel disease. United European Gastroenterol J. 2018;6(1):112-22. doi: 10.1177/2050640617708953.

67. Mima K, Nakagawa S, Sawayama H, Ishimoto T, Imai K, Iwatsuki $\mathrm{M}$, et al. The microbiome and hepatobiliary-pancreatic cancers. Cancer Lett. 2017;402:9-15. doi: 10.1016/j. canlet.2017.05.001.

68. Zhou D, Wang J, Weng M, Zhang Y, Wang X, Gong W, et al. Infections of Helicobacter spp. in the biliary system are associated with biliary tract cancer: A meta-analysis. Eur J Gastroenterol Hepatol. 2013;25(4):447-54. doi: 10.1097/ MEG.0b013e32835c0362.

69. Murphy G, Michel A, Taylor PR, Albanes D, Stephanie J, Virtamo J, et al. Association of seropositivity to Helicobacter species and biliary tract cancer in the ATBC study. 2014;60(6):1963-71. doi: 10.1002/hep.27193.

70. Takayama S, Takahashi H, Matsuo Y, Okada Y, Takeyama $\mathrm{H}$. Effect of helicobacter bilis infection on human bile duct cancer cells. Dig Dis Sci. 2010;55(7):1905-10. doi: 10.1007/ s10620-009-0946-6.

71. Chng KR, Chan SH, Ng AHQ Li C, Jusakul A, Bertrand D, et al. Tissue microbiome profiling identifies an enrichment of specific enteric bacteria in Opisthorchis viverrini associated Cholangiocarcinoma. EBioMedicine. 2016;8:195-202. doi: 10.1016/j.ebiom.2016.04.034.
72. Avilés-Jiménez F, Guitron A, Segura-López F, MéndezTenorio A, Iwai S, Hernández-Guerrero A, et al. Microbiota studies in the bile duct strongly suggest a role for Helicobacter pylori in extrahepatic cholangiocarcinoma. Clin Microbiol Infect. 2016;22(2):178.e11-178.e22. doi: 10.1016/j. cmi.2015.10.008.

73. Rakic M, Patrlj L, Kopljar M, Klicek R, Kolovrat M, Loncar B, et al. Gallbladder cancer. Hepatobiliary Surg Nutr. 2014;3(5):221-6. doi: 10.3978/j.issn.2304-3881.2014.09.03.

74. Rustagi T, Dasanu CA. Risk factors for gallbladder cancer and cholangiocarcinoma: Similarities, differences and updates. J Gastrointest Cancer. 2012;43(2):137-47. doi: 10.1007/ s12029-011-9284-y.

75. Koshiol J, Wozniak A, Cook P, Adaniel C, Acevedo J, Azócar L, et al. Salmonella enterica serovar Typhi and gallbladder cancer: A case-control study and meta-analysis. Cancer Med. 2016;5(11):3310-235. doi: 10.1002/cam4.915.

76. Elsalem L, Jum'ah AA, Alfaqih MA, Aloudat O. The bacterial microbiota of gastrointestinal cancers: Role in cancer pathogenesis and therapeutic perspectives. Clin Exp Gastroenterol. 2020;13:151-85. doi: 10.2147/CEG.S243337.

77. Ruby T, Mclaughlin L, Gopinath S, Monack D. Salmonella's long-term relationship with its host. FEMS Microbiol Rev. 2012;36(3):600-15. doi: 10.1111/j.1574-6976.2012.00332.x.

78. Scanu T, Spaapen RM, Bakker JM, Pratap CB, Wu L, Hofland I, et al. Salmonella manipulation of host signaling pathways provokes cellular transformation associated with gallbladder carcinoma. Cell Host Microbe. 2015;17(6):763-74. doi: 10.1016/j.chom.2015.05.002.

79. Tsuchiya Y, Loza E, Villa-Gomez G, Trujillo CC, Baez S, Asai $\mathrm{T}$, et al. Metagenomics of microbial communities in gallbladder bile from patients with gallbladder cancer or cholelithiasis. Asian Pac J Cancer Prev. 2018;19(4):961-7. doi: 10.22034/APJCP.2018.19.4.961.

80. Jergens AE, Wilson-Welder JH, Dorn A, Henderson A, Liu Z, Evans RB, et al. Helicobacter bilis triggers persistent immune reactivity to antigens derived from the commensal bacteria in gnotobiotic C3H/HeN mice. Gut. 2007;56(7):934-40. doi: 10.1136/gut.2006.099242. 